\title{
Somatotype in high performance female netball players may influence player position and the incidence of lower limb and back injuries
}

\author{
Diana M Hopper
}

\begin{abstract}
Aims-To investigate the relation between somatotype, performance characteristics, and the incidence of injury during the Australian Netball Championships. Method-Two hundred and forty high performance netball players competed at the Australian Netball Championships in which 213 (89\%) were measured using the Heath-Carter somatotype scale. During these championships, in conjunction with the injury assessments, data analysis included a three factor analysis of variance (level of competition, playing position, and injury) for the dependent somatoype variables (endomorphy, mesomorphy, and ectopmorphy), and the level of significance was set at 0.05 .

Results-For the three dependent somatotype variables, there were no main effects between endomorphy, mesomorphy, and ectopmorphy and the incidence of injury. However, for the mesomorphy and ectomorphy variables, significant main effects for the playing position were found. No main effects existed between the somatotype variables and levels of competition.

Conclusion-The somatotype variables did not influence the incidence of injury, but mesomorphy and ectopmorphy did influence the different playing positions. (Br F Sports Med 1997;31:197-199)
\end{abstract}

Keywords: somatotype; netball; playing positions; competition

In many sports, physical body type profiling has often been used to identify potential talent and suitability of athletes for certain sports and specific events. Sheldon ${ }^{1}$ was one of the original researchers who developed the idea of assessing and relating somatotype to certain Olympic sports. Later, Tanner ${ }^{2}$ studied the physique of different categories of sportsmen participating in the Olympics and stressed the importance of physique in performance. Since these early studies, anthropometric measurements and somatotype evaluations have become important in the assessment of talent identification for various sporting requirements for male oriented sports. Limited investigations into female body types have been confined to team sports such as hockey. Wilsmore ${ }^{3}$ investigated the relation of body type of female hockey players to playing position and level of competition and reported that mesomorphy was the dominant somatotype component for all these players.

Netball is another female team sport for which researchers have investigated kinanthropometric and performance variables. ${ }^{4}$ These two studies were unique as it was the first time that netball players had been objectively measured and their body types evaluated. Last year, Australia celebrated winning the World Netball Championship held at Birmingham in the United Kingdom. During these championships, the Australian goal shooter ruptured her anterior cruciate ligament, which raised the issue of whether the injury was related to the player's body type. There appears, however, to be a minimal literature on the relation between somatotype, performance characteristics, and the incidence of injury in high performance netball players. To overcome these deficiencies in the literature, this study investigates the relation between somatotype, performance characteristics, and the incidence of injury at the Australian Netball Championships.

\section{Methods}

SUBJECTS

In August 1988, 240 high performance netball players participated in the All Australian

Table 1 Physical and morphological characteristics of elite netball players. Values are mean (SD)

\begin{tabular}{llllllll}
\hline Level & No & Age (years) & Height $(\mathrm{cm})$ & Mass $(\mathrm{kg})$ & Endomorph & Mesomorph & Ectomorph \\
\hline "Open" & 68 & $23.7(3.59)$ & $173.5(6.35)$ & $66.17(7.99)$ & $3.6(1.0)$ & $3.5(1.3)$ & $2.9(1.0)$ \\
U/21 & 77 & $19.2(2.23)$ & $173.1(5.81)$ & $66.89(7.34)$ & $3.9(1.0)$ & $3.4(1.3)$ & $2.6(0.9)$ \\
U/16 & 68 & $14.8(0.44)$ & $169.1(6.07)$ & $58.98(6.20)$ & $4.2(1.0)$ & $3.4(1.1)$ & $2.5(0.9)$ \\
\hline
\end{tabular}


National Netball Championships held in Perth, Australia. There were three different levels of competition which will be referred to as "Open", U/21, and U/16 (schoolgirls). The "Open" players had a mean age of 23.7 years, the $U / 21$ players a mean age of 19.2 years, and the $U / 16$ players a mean age of 14.8 years. The "Open" and U/21 players were similar in height $(173 \mathrm{~cm})$ and mass $(66 \mathrm{~kg})$, with the younger players recording lower values for height (169 $\mathrm{cm})$ and weight $(59 \mathrm{~kg})$ as shown in table 1 .

Before the championships, 213 of the 240 players $(89 \%)$ consented to have measurements taken in accordance with the HeathCarter somatotype rating scale. During the championships, the team physiotherapists assessed, treated, and recorded data on all players who sustained lower limb and back injuries. Details of these injury data have already been published by Hopper and Elliott ${ }^{6}$; however, a subset of these data has now been analysed comparing the relation of somatotype, performance characteristics, and the incidence of injury.

This study was approved by the Curtin University of Technology Human Research Ethics Committee. Written informed consent was obtained from the players, who were allowed to withdraw at any time of the testing without fear of prejudice. A guarantee of anonymity and confidentiality was given.

\section{SOMATOTYPE ASSESSMENT}

Somatotype ratings of endomorphy (adiposity), mesomorphy (muscularity), and ectomorphy (linearity) were calculated for all subjects based on the Heath-Carter method. ${ }^{7}$ To obtain these ratings, skinfold measurements for the triceps, subscapular, and suprailiac were taken in millimetres with Harpenden skinfold calipers. Height was measured with a stadiometer, upper arm girth and calf girth were measured with a constant tension tape, and bone widths of the humerus at the distal end and the femur at the distal end were measured with bone calipers. Body mass was measured using Avery scales, and, together with height, the Inverse Pondex Index was calculated. The criterion measure in each case was the average of three trials on the preferred side of the body. Reliability coefficients to determine tester competence had been previously established using a test-retest method. This indicated that

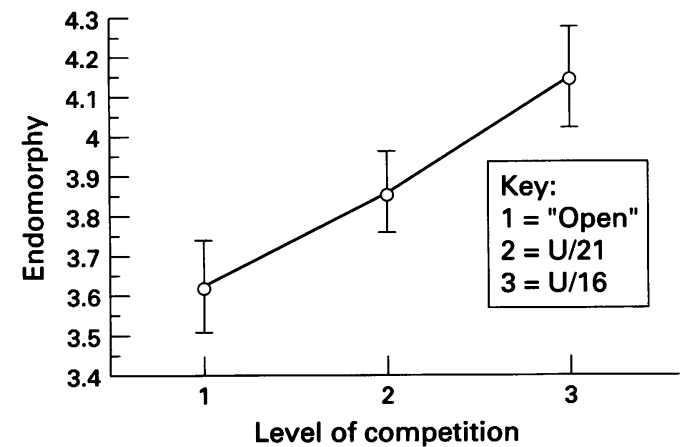

Figure 1 Interaction between endomorph somatotype and level of competition

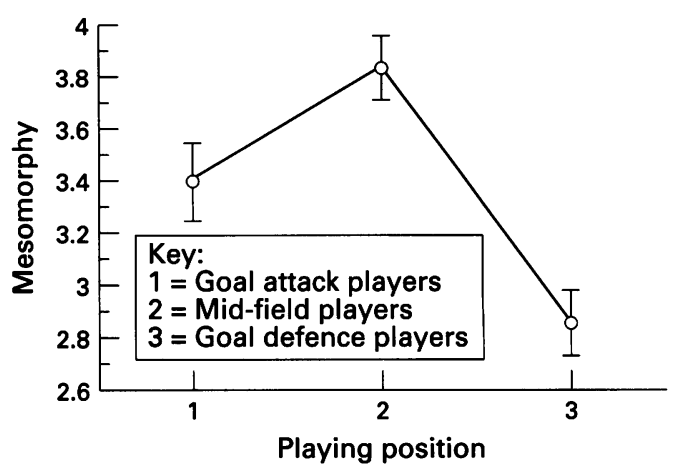

Figure 2 Interaction between mesomorph somatotype and playing position

for all measures the tester reliability was between 0.95 and 0.98 .

\section{ANALYSIS OF DATA}

Descriptive data assessed the means and standard deviations for the level of competition, age, height, and mass including the somatotype variables of endomorph, mesomorph, and ectomorph. A three factor analysis of variance (level of competition: "Open", U/21, $\mathrm{U} / 16$ ), playing position (goal attack, mid-field, goal defence), and injury status (injured and non-injured) was used for each of the dependent somatotype variables. If a significant main effect was found, then Scheffe's S post hoc comparisons were performed to determine which groups were significantly different. To assess the statistical significance for all analyses, an alpha level of 0.05 was set.

\section{Results}

Fifty two of the 213 (24\%) players presented with a lower limb or back injury during the championships.

For the first dependent variable, endomorphy, there was no significant difference between playing position $\left(F_{2,195}=0.92, \mathrm{P}=0.39\right)$ and injury status $\left(F_{2,195}=0.53, \mathrm{P}=0.46\right)$, but there was a significant trend between level of competition $\left(F_{2,195}=2.75, P=0.066\right)$. Scheffe's $S$ post hoc comparisons showed that there was a significant $(P<0.01)$ increase in endomorphy in the younger players (U/16) compared with the most experienced players ("Open"). There were no differences between "Open" and U/21 players and between $U / 21$ and $U / 16$ players. Figure 1 shows these trends.

For the second dependent variable, mesomorphy, there was no significant difference

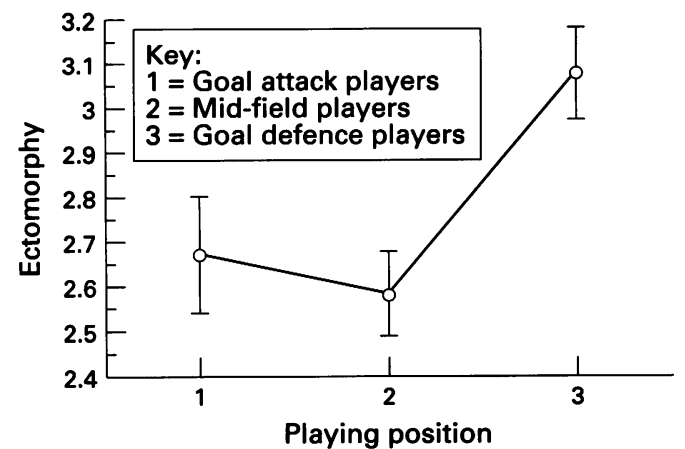

Figure 3 Interaction between ectomorph somatotype and playing position 
between level of competiton $\left(F_{2,195}=0.19, \mathrm{P}=\right.$ $0.81)$ and injury status $\left(F_{2,195}=0.23, \mathrm{P}=0.63\right)$, but there was a significant difference between playing position $\left(F_{2,195}=9.64, \mathrm{P}=0.00\right)$. Scheffe's $S$ post hoc comparisons showed that there were significant differences between midfield and goal attacks $(P<0.01)$ and between mid-field and goal defence $(P<0.01)$ players. There were no differences between goal attack and defence players. Figure 2 shows these differences.

For the third dependent variable, ectomorphy, there was no significant difference between level of competition $\left(F_{2,195}=0.44, \mathrm{P}=\right.$ $0.64)$ and injury status $\left(F_{2,195}=1.89, \mathrm{P}=0.16\right)$, but there was a significant difference between playing position $\left(F_{2,195}=5.84, \mathrm{P}=0.00\right)$. Scheffe's $S$ post hoc comparisons showed that there were significant differences between goal defence and mid-field $(P<0.01)$ and between goal defence and goal attack $(P<0.01)$ players. There were no differences between goal attack and mid-field players. Figure 3 shows these differences.

\section{Discussion}

Physical anthropometric data have often been used to assess the relation between successful performance in sport and body build. ${ }^{3}$ For this reason somatotype for the different playing positions was assessed over all the three levels of competition. Significant differences were found for mesomporphy and ectomorphy somatotype components and different playing positions. In the mesomorphic component, the mid-field players had a different somatotype from the goal attack and goal defence positions. These mid-field netball players were more muscular and robust to meet the demands of short accelerated movements linking defensive play and attacking manoeuvres. Goal defence players were significantly different from the goal attack and mid-field players for the ectomorphic component. These players had increased linearity measures which gives an advantage when rebounding an attempted goal, leaping to catch a pass, or making a defensive interception of the ball.

Somatotype profiling is considered important in determining an athlete's potential and suitability for a specific sport. The present study found that there were no relations between any of the somatotype components and the incidence of injury during the championships. In contrast, when Hopper et al compared somatotype ratings with injury incidence during an entire winter season, they found that there was no difference between the injured and non-injured for the mesomorphic and ectomorphic components but the injured players had a significantly lower endomorphic component when compared with the noninjured players.

\section{Conclusions}

This study confirms that high performance female netball players do have different somatotypes for the selected playing positions, and that there is no relation between endomorphic, mesomorphic, and ectomorphic somatotype variables and the incidence of injury.

Sincere thanks are expressed to all the netballers and the All Australian Netball Association without whom this study would not have been possible.

\section{Sheldon WH. The varieties of human physique. New York: Harper, 1940 \\ 2 Tanner JM. The physique of the Olympic athlete. London: George Allen \& Unwin, 1964. \\ 3 Wilsmore RG. The body type of female hockey players involved in different playing positions and levels of compe- tition. Aust f Sci Med Sport 1987;19:26-8. \\ 4 Elliott B, Smith J. The relationship of selected biomechanic and anthropometric measures to accuracy in netball shoot- ing. Fournal of Human Movement Studies 1983;9:171-87. \\ 5 Hopper DM, Hopper JL, Elliott BC. Do selected kinanthro- pometric and performance variables predict injuries in female netball players? I Sports Sci 1995;13:213-22. \\ 6 Hopper D, Elliott, B. Lower limb and back injury patterns of elite netball players. Sports Med 1993;16:148-63. \\ 7 Carter JEL. The Heath-Carter somatotype method. San Diego: San Diego State University Press, 1980.}

\section{Commentary}

Hopper should be applauded as she continues to build on her earlier work and the work of others in Australia and New Zealand. Australia are the reigning world champions of 1991 and 1995, and as such have received much more media attention than England, for example, who finished fourth in the last two World Championships. Many workers have highlighted the seriousness of the injury problem including Egger, ${ }^{1}$ who estimated that knee injuries accounted for $20 \%$ of all injures among netball players and that the estimated cost of all injuries in this group was about \$12-14.5 million. It is vital, therefore, that further research should examine, in depth, factors that may affect injury. Other identified factors include landing patterns, ${ }^{2}$ footfall patterns and passing height, ${ }^{3}$ playing surfaces, footwear, and footfall patterns. ${ }^{4}$

PATSY ROCHESTER

1 Egger G. Sports injuries in Australia. Causes, costs and prevention-a report to the national better health program. Sydney, Australia: Centre for Health Promotion and Research, October 1990.

2 Hopper D, Lo SL, Kirkham C, Elliot B. Landing patterns in netball; analysis of an international game. Br f Sports Med 1992;26: 101-6.

3 Neal RJ, Sydney-Smith M. The effects of footfall patterns and passing height on ground reaction forces in netball. Aust $\mathcal{F}$ Sci Med Sport 1992;24:73-8.

4 Steele JR. Biomechanical factors affecting performance in netball: implications for improving performance and injury reduction Sports Med 1990;10:88-102. 